\title{
Original Research \\ Health professionals' knowledge, attitude and practices towards pharmacovigilance in Nepal
}

\author{
Subish PALAIAN, Mohamed I. IBRAHIM, Pranaya MISHRA. \\ Received (first version): $28-$ Oct-2010 Accepted: 14-Nov-2011
}

\begin{abstract}
${ }^{\star}$
Pharmacovigilance can be helpful in protecting consumers from harmful effects of medicines. Healthcare professionals should consider Adverse Drug Reaction (ADR) reporting as their professional obligation and should be aware of the existing pharmacovigilance mechanisms in their countries. In Nepal, pharmacovigilance activities were initiated in 2004.

Objectives: The present study evaluated the knowledge, attitude and practices (KAP) of the healthcare professionals towards ADRs and pharmacovigilance in Manipal Teaching Hospital (MTH), a tertiary care teaching hospital attached to the regional pharmacovigilance center in western Nepal.

Methods: A cross-sectional study was carried out in 2007 using a pretested (Cronbach alpha=0.72) questionnaire having 25 questions (15 questions on knowledge, 5 on attitude and 5 on practice). The correct/positive responses were given a score of ' 2 ' and the wrong/negative responses ' 1 ', maximum possible score of ' 50 '.

Results: A total of 131 responses were obtained among which 42 were incomplete and remaining 89 [females $49(55.1 \%)$ ] were analyzed. Of the 89 professionals, $29(32.6 \%)$ were doctors, 46 (51.8) nurses and $14(15.7 \%)$ pharmacists. The mean age was $28.32(S D=8.46)$ years and the median (interquartile range) of duration of the service 14.5 (6-36) months. The total KAP scores was 40.06 $(\mathrm{SD}=3.51)$ for doctors, $38.92(\mathrm{SD}=4.83)$ for pharmacists, and 35.82 ( $S D=3.75)$ for nurses. Among the 89 professionals, 59 (62.3\%) had not reported even a single ADR to the pharmacovigilance center.

Conclusion: The healthcare professionals at the MTH had a poor KAP towards ADRs and pharmacovigilance and there is a need for educational and awareness intervention for these professionals.
\end{abstract}

Keywords: Adverse Drug Reaction Reporting Systems. Attitude of Health Personnel. Nepal.

\footnotetext{
* Subish PALAIAN. Discipline of Social and Administrative Pharmacy. School of Pharmaceutical Sciences, Universiti Sains Malaysia. Penang (Malaysia).

Mohamed I. IBRAHIM. Department of Pharmacy Practice, College of Pharmacy, Qassim University. Al Qassim (Saudi Arabia.).

Pranaya MISHRA. Department of Pharmacology, Saba University School of Medicine. Saba, (NetherlandsAntilles).
}

\author{
CONOCIMIENTOS, ACTITUDES Y \\ PRÁCTICAS DE LOS PROFESIONALES DE \\ LA SALUD HACIA LA \\ FARMACOVIGILANCIA EN NEPAL
}

\section{RESUMEN}

La farmacovigilancia puede ser útil para proteger a los consumidores de los efectos dañinos de los medicamentos. Los profesionales de la salud deberían considerar la comunicación de reacciones adversas de medicamentos (RAM) como una obligación profesional y deberían conocer los mecanismos de farmacovigilancia que existen en sus países. En Nepal, las actividades de farmacovigilancia comenzaron en 2004. Objetivos: El presente estudio evaluó el conocimiento, actitudes y prácticas (KAP) de los profesionales de la salud hacia las RAM y la farmacovigilancia en el Hospital Universitario de Manipal (MTH), un hospital universitario terciario ligado al centro regional de farmacovigilancia del Oeste de Nepal.

Métodos: Se realizó un estudio transversal en 2007 usando un cuestionario pre-evaluado (alfa de Cronbach $=0,72$ ) que tenía 25 preguntas ( 15 sobre conocimiento, 5 sobre actitudes y 5 sobre práctica). A las preguntas correctas se les dio una puntuación de ' 2 ' y a las respuestas incorrectas/negativas se les dio un ' 1 ', con una puntuación máxima de 50.

Resultados: Se obtuvieron un total de 131 respuestas de las que 42 estaban incompletas y las restantes 89 se analizaron [49 mujeres $(55,1 \%)]$. De los 89 profesionales, $29(33,6 \%)$ eran médicos, 46 $(51,8 \%=$ enfermeras y $14(15,7 \%)$ farmacéuticos. La media de edad era de 28,32 años $(\mathrm{DE}=8,46)$ y la media (rango intercuartílico) de la duración en el servicio fue 14,5 meses (6-36). Las puntuaciones totales de KAP fueron 40,06 (DE=3,51) para médicos, 39,92 $(\mathrm{DE}=4,83)$ para farmacéuticos y $35,82(\mathrm{DE}=3,75)$ para enfermeras. Entre los 89 profesionales, $59(62,3 \%)$ no comunicaron ni una sola RAM al centro de farmacovigilancia. Conclusión: Los profesionales de la saludo del MTH tienen pobre KAP sobre las RAM y la farmacovigilancia, y se necesita una intervención educativa y sobre el conocimiento para estos profesionales.

Palabras clave: Sistemas de Registro de Reacción Adversa a Medicamentos. Actitud del Personal de Salud. Nepal. 


\section{INTRODUCTION}

Adverse Drug Reactions (ADRs) are associated with a significant morbidity and mortality. ${ }^{1-4}$ Recent estimates suggest ADRs to be the fourth major cause of death in the United States (US). ${ }^{3}$ In order to identify the offending drugs causing ADRs, several countries have initiated pharmacovigilance programs in the recent past. Because of the variation in drug response among individuals, prescribing habits, drug regulatory system, and availability of drugs, it has been recommended for every country to set up their own pharmacovigilance programs. ${ }^{5}$ Most countries in the world have, therefore, established formal procedures to encourage healthcare professionals to report suspected ADRs they encounter in their clinical practice to their national drug regulatory authority or to the appropriate pharmaceutical manufacturer. ${ }^{6}$

Spontaneous ADR reporting schemes have been a major source of information in pharmacovigilance. ${ }^{7}$ Spontaneous reporting can prevent the occurrence of new medicine tragedies and can improve the safety labeling of pharmaceutical products. ${ }^{8,9}$ However, spontaneous reporting schemes are associated with relatively low levels of reporting. It is likely that less than $10 \%$ of serious reactions are notified. Problems of motivating reporters, commitment, and lack of clarity about what should be reported and fear of recrimination for errors may be some of the factors responsible. The scheme operates on the basis of reporting all ADRs despite uncertainty about a causal relationship. ${ }^{10} \mathrm{~A}$ review of national spontaneous reporting schemes shows that spontaneous reports are accepted from doctors, dentists and pharmacists in all of the countries surveyed. However, the role of other health professionals and the general public was found to vary. The types of reactions for which reports are requested, and the products covered were different. The numbers of reports varies considerably from a few hundred each year in South Africa to over 20000 in the US. ${ }^{11}$ The number of ADRs reported to VigiFlow online pharmacovigilance database [the World Health Organization (WHO) global database for ADR reports] has been less than 25 from countries like Congo, Cyprus, and Uzbekistan. ${ }^{12}$

The success of a pharmacovigilance program depends upon the involvement of the healthcare professionals and reporting the ADRs. Being the key healthcare professionals, the doctors, nurses and pharmacists have immense responsibility in reporting ADRs and strengthening the pharmacovigilance mechanisms that exists in their vicinity. Providing information on suspected ADRs is as much a moral duty for the doctor as other aspects of patient care. ${ }^{13} \mathrm{~A}$ nurse is the first member to observe the patient while the patient is admitted in the hospital. The nurse can even teach the patient and attendants the signs and symptoms that should be reported immediately versus those that can be held until the next visit unless it is bothersome. ${ }^{14}$ The pharmacist is often the last member of the healthcare team to see a patient before he takes the drug without direct medical supervision. The pharmacist's role is to promote the development, maintenance and ongoing evaluation of a program to reduce the risks of ADRs by detecting, reporting and assessing any suspected ADRs. A pharmacist can educate the physicians and nurses and can encourage compliance with the ADR reporting program. ${ }^{15}$

Although pharmacovigilance programs are successful in improving drug use patterns, underreporting of ADRs is felt as a major problem. ${ }^{10}$ There is also strong evidence of significant and widespread under-reporting of ADRs to spontaneous reporting systems including serious or severe ADRs. ${ }^{16}$ One of the reasons for underreporting might be a poor understanding of the healthcare professionals towards the existing pharmacovigilance program. In Hong Kong, most pharmacists were not aware of any ADR reporting system. ${ }^{17}$ In Malaysia, lack of awareness about the existence, function and purpose of national ADR reporting were the major reasons for underreporting. ${ }^{18}$ Researchers from Portugal found a strong association between attitudes associated with under-reporting. ${ }^{19}$ In China, healthcare professionals had only a little basic knowledge of $A D R$ and about the existing voluntary reporting system and were the major reasons for underreporting. ${ }^{6}$ In Nigeria, the commonest factors responsible for under-reporting were lack of knowledge on the availability of reporting forms and ignorance of the reporting procedure. ${ }^{20} \mathrm{~A}$ recent systematic review reported knowledge and attitudes of health professionals to be strongly related with reporting of ADRs. ${ }^{21}$

In Nepal, the pharmacovigilance program was started in the year 2004 and the national center has received more than 300 ADR reports over the span of four and a half years. This program is mainly hospital based and thus, has got limited coverage. There are not much of awareness programs for the healthcare professionals regarding the inception and the functioning of the program. The success of a pharmacovigilance program depends upon the participation of the healthcare professionals. The healthcare professionals should be aware of the existing pharmacovigilance programs and regulations controlling drug safety in their country. In Nepal, the pharmacovigilance program is in the stage of infancy and thus, there is a need to promote the program among the healthcare professionals. Findings from studies conducted abroad revealed ADR reporting to be linked to the Knowledge, Attitude and Practices (KAPs) of the healthcare professionals. ${ }^{17-19}$ Thus, it is very essential for the healthcare professionals to be knowledgeable so as to play vital role in the ADR reporting programs. Similarly, in order to improve an existing pharmacovigilance program, there is a need to improve healthcare professionals' KAP. Prior to carrying out any intervention, it is necessary to evaluate the baseline KAP of the healthcare professionals regarding $A D R$ monitoring and pharmacovigilance so that the intervention can be targeted, based on the specific findings. In Manipal Teaching Hospital (MTH), the pharmacovigilance program has been in place since 2004. The KAP of 
the healthcare professionals at MTH towards ADRs and pharmacovigilance is not known. Evaluating their KAP can help in developing strategies to improve the program in the hospital. Similarly, this information can be useful for the other regional pharmacovigilance centers in the country to improve their pharmacovigilance activities. Hence, the present study was carryout to analyze the knowledge, attitude and practice of healthcare professionals regarding adverse drug reactions and pharmacovigilance in general, and to evaluate the association between, (if any) the knowledge, attitude and practice of healthcare professionals with their demographic profiles.

\section{METHODS}

Study design: A cross-sectional survey was carried out to evaluate the KAP among doctors, nurses and pharmacists working at MTH towards ADRs and pharmacovigilance.

Study site: The study was carried out at MTH, a 700 bed tertiary care private hospital located in the western region of Nepal. The regional pharmacovigilance center for the western regional of Nepal is located at this hospital.

Study population and sampling: During the study period (September 2007) there were a total of 185 healthcare professionals (14 pharmacists, 116 nurses and 55 doctors) working in the hospital. All of them were selected.

Inclusion and exclusion criteria: All the healthcare professionals (doctors, nurses and pharmacists) working in the MTH during the study period were included. The healthcare professionals who were not willing to participate in the study and the ones who were on leave were excluded.

Study tools: For the purpose of the study, a KAP questionnaire was used. This questionnaire was newly developed. It consisted of a total of 25 questions. Among these questions, 15 (Qs: 1-5, 8$12,17,18,21,24,25)$ were related to the 'knowledge', 5 (Qs: 6, 7, 16, 22, 23) were related to 'attitude' and the remaining 5 (Qs: $13-15,19-20$ ) were related to the 'practice' aspects. The KAP questionnaire was designed by the researchers of the pharmacovigilance center in MTH. The initial draft was made and circulated to the members of the research team and modifications were carried out as per the suggestions. Each correct answer and each positive response were given a score of ' 2 ' whereas the negative response or wrong answers were given a score of ' 1 '. The maximum possible score was ' 50 '.

Questionnaire validation: The reliability of the questionnaire was measured by pretesting the questionnaire with 24 healthcare professionals (10 doctors, 2 pharmacists and 12 nurses) working at MTH. Each correct answer and each positive response were given a score of ' 1 ' whereas the negative response or wrong answers were given a score of ' 0 '. The maximum possible score was ' 25 '. The Cronbach alpha value of the questionnaire was calculated to be 0.72 in the pilot study ${ }^{22}$ and no modifications have been carried out.

Modality of obtaining the knowledge, attitude and practice responses: Different modalities were applied for obtaining responses from different healthcare professionals. Doctors were contacted directly in their department and the questionnaires were distributed. The responses from the nurses were collected during an educational program organized for the nurses by the Department of Medicine. A few nurses who were not present during the program were contacted personally and their responses were collected. The responses from pharmacists were collected during a Continuing Pharmacy Education (CPE) program conducted for them by the Department of Hospital and Clinical Pharmacy. Every healthcare professional was given 30 minutes to fill up the questionnaire. Any clarification needed in understanding the questionnaire was provided. Additional time was given for the professionals who requested for extra time in filling up the questionnaire.

Data analysis: The filled KAP questionnaires were analyzed as per the study objectives. The various parameters such as 'sex distribution', 'age distribution', 'professional status', 'educational qualifications', 'worksite', 'duration of service' and the 'knowledge, attitude and practice scores' were analyzed. The data obtained were entered in Microsoft excel spread sheet and were analyzed. SPSS version 12.0.1 was used to conduct the descriptive statistics. The mean, SD and median total score were compared among different subgroups of respondents. A Mann-Whitney $U$ test was used for comparing the scores of the subgroups with 'two groups' and a Kruskal-Wallis test for the subgroups with 'more than two groups'. All tests were carried out at a priori significance level of 0.05 .

\begin{tabular}{|c|c|}
\hline & Frequency (\%) \\
\hline $\begin{array}{r}\text { Male } \\
\text { Female }\end{array}$ & $\begin{array}{l}40(44.9) \\
49(55.1)\end{array}$ \\
\hline $\begin{array}{r}\text { Up to } 20 \\
21-30 \\
31-40 \\
41-50 \\
51-60 \\
\text { Above } 60 \\
\text { Not available }\end{array}$ & $\begin{array}{c}6(6.7) \\
56(62.9) \\
14(15.7) \\
2(2.2) \\
1(1.1) \\
2(2.2) \\
8(9.0)\end{array}$ \\
\hline $\begin{array}{r}\text { Professional status } \\
\text { Doctors } \\
\text { Nurses } \\
\text { Pharmacy practitioners * }\end{array}$ & $\begin{array}{l}29(32.6) \\
46(51.7) \\
14(15.7)\end{array}$ \\
\hline $\begin{array}{l}\text { * }=\text { It includes the pharmacists and } t \\
\text { who obtained orientation in pharma } \\
\text { pharmacy }\end{array}$ & $\begin{array}{l}\text { rofessionals } \\
\text { and practicing }\end{array}$ \\
\hline
\end{tabular}

\section{RESULTS}

Among the total 185 healthcare professionals working in the hospital only $70.8 \%(n=131)$ provided their responses. Of these responses $67.9 \%(n=89)$ were analyzed and the rest $32 \%(n=42)$ were not included in the analysis because of incomplete 


\begin{tabular}{|c|c|c|}
\hline Questions & Number & Percentage \\
\hline Do you think reporting adverse drug reaction is necessary? & 86 & 96.6 \\
\hline $\begin{array}{l}\text { Do you think reporting adverse drug reaction should be made } \\
\text { mandatory? }\end{array}$ & 63 & 70.8 \\
\hline $\begin{array}{l}\text { The important factor necessary to report an adverse drug } \\
\text { reaction is }\end{array}$ & 58 & 65.2 \\
\hline $\begin{array}{l}\text { The healthcare professional responsible for reporting adverse } \\
\text { drug reaction in a hospital is }\end{array}$ & 72 & 80.9 \\
\hline Do you find any difficulty in reporting adverse drug reactions? ${ }^{*}$ & 16 & 18.0 \\
\hline
\end{tabular}

questions. It was found that only one third $(n=30$; $33.7 \%)$ of the respondents had ever submitted an ADR report to the pharmacovigilance center. The details regarding the responses of the healthcare professionals for these questions are listed in Table 6.

Reasons for not reporting an adverse drug reaction by the professionals: Out of total 89 participants, 59 had not reported even a single ADR to the pharmacovigilance center. Among these, 28 of them gave reasons for not reporting an ADR. The reasons for underreporting were 'not come across an ADR' $57.1 \%(n=16)$; 'the ADRs were common and minor' $14.3 \% \quad(n=4)$; 'not aware of the pharmacovigilance center in Manipal Teaching Hospital' $14.3 \% \quad(n=4)$; 'usually we inform to concerned doctors' $10.7 \%(n=3)$; 'no idea where to report' $3.6 \%(n=1)$.

Respondents' views on important factor necessary to report an adverse drug reaction: The important factors perceived as necessary to report an adverse drug reactions were, knowledge regarding drugs $20.2 \%(n=18)$; patient cooperation $7.9 \%(n=7)$; time $4.5 \%(n=4)$; availability of adverse drug reaction forms $1.2 \%(n=1)$; time and availability of adverse drug reaction forms $1.1 \%(n=1)$; and $65.2 \%(58)$ of the respondents considered all of these factors to be necessary.

Respondents' views on healthcare professionals responsible for reporting ADRs: Majority $(n=72$; $80.9 \%$ ) of the healthcare professionals were in opinion that ADR reporting is the combined responsibility of doctors, nurses, pharmacists and medical interns, and few mentioned it to be the responsibility of nurses $(n=7 ; 7.9 \%)$, followed by doctors $(n=5 ; 5.7 \%)$, pharmacists $(n=4 ; 4.6 \%)$, and medical interns $(n=1 ; 1.1 \%)$.

\section{DISCUSSION}

This is the first study in Nepal that evaluated the KAP of healthcare professionals regarding ADRs and pharmacovigilance. Overall, the KAP scores of the professionals were low. Doctors and pharmacists had a slightly higher score than the nurses. Among doctors and pharmacists, doctors had relatively higher scores.

Pharmacovigilance deals with detection, assessment, understanding and prevention of adverse effects or any other drug related problems. The ultimate aim of pharmacovigilance is to ensure patient safety and rational use of medicines, once a new medicine is released for general use in the society. The most important outcome of pharmacovigilance is the prevention of patients being affected unnecessary negative consequences of pharmacotherapy. ${ }^{23}$

Pharmacovigilance programs have played a major role in detection of ADRs and banning of several drugs from the market. However, under-reporting of ADRs is one of the major problems associated with pharmacovigilance programs. ${ }^{24}$ It is known that spontaneous reporting programs (one of the most widely used methods of pharmacovigilance) are associated with relatively low levels of reporting. The scheme operates on the basis of reporting all ADRs despite uncertainty about a causal relationship. Even in countries like the United Kingdom (UK), where pharmacovigilance programs are well established, a high level of under-reporting is documented. ${ }^{25}$

The major reasons for under-reporting of ADRs are lack of knowledge about the reporting procedure, unavailability of the reporting center mailing address, unavailability of the ADR report form, lack of knowledge of the existence of a national ADR reporting system, and belief that the ADR in question was already well known, ADR is not serious, uncertainty concerning the causal relationship between the $A D R$ and the drug, forgetting to report the ADR and lack of time and ignorance of reporting procedure..$^{10,17,19,20}$ In the present study, the reasons for under-reporting were that the healthcare professionals had not come across an ADR (57.1\%), the ADRs were common and minor (14.3\%) and lack of awareness about the pharmacovigilance center in the hospital (14.3\%).

\begin{tabular}{|l|c|c|}
\hline \multicolumn{1}{|c|}{ Table 6. Responses of the professionals to the practice related questions (professionals answering 'yes') } \\
\hline \multicolumn{1}{|c|}{ Questions } & Number & Percentage \\
\hline Have you ever read any article regarding adverse drug reactions? & 58 & 65.2 \\
\hline $\begin{array}{l}\text { Have you ever reported an adverse drug reaction to the } \\
\text { pharmacovigilance center at Manipal Teaching Hospital? }\end{array}$ & 30 & 33.7 \\
\hline $\begin{array}{l}\text { Have you ever seen any patient experiencing an adverse drug } \\
\text { reaction? }\end{array}$ & 63 & 70.08 \\
\hline Do you follow any approach to prevent adverse drug reactions? & 61 & 68.5 \\
\hline Have you ever prevented an adverse drug reaction from occurring? & 35 & 39.3 \\
\hline
\end{tabular}


One of the better means of overcoming underreporting is to increase the KAP of the healthcare professional regarding ADR monitoring and pharmacovigilance programs. A study from India reported that the KAP regarding ADR monitoring was low among healthcare professionals and authors recommended for improvement. ${ }^{26}$ A survey among medical residents in France showed that the majority of them had minimal knowledge regarding pharmacovigilance. ${ }^{27}$ A study from Italy reported that doctors had little information concerning ADRs and ADR reporting systems. ${ }^{28}$ Another study from India also identified the awareness about pharmacovigilance programs and the knowledge of ADR reporting to be very low among the doctors. ${ }^{29}$ These findings suggest the need for interventions to improve the KAP of the healthcare professionals. It is also recommended that pharmacists play a great role in educating other healthcare professionals regarding prevention, detection and reporting of ADRs. ${ }^{10} \mathrm{~A}$ lower KAP score documented in this study further necessitates the need for pharmacist mediated intervention in order to improve the KAP of the healthcare professionals in this regard. The regional pharmacovigilance center at the hospital had recently come out with a booklet on pharmacovigilance for the healthcare professionals. ${ }^{30}$ The objective of the booklet was to improve the KAP of the healthcare professionals regarding ADR monitoring and pharmacovigilance.

In this study, $60.7 \%$ of the healthcare professionals knew the location of the regional pharmacovigilance center. This finding was reasonably similar to the observations made in both developing and developed countries. In Malaysia, about $40 \%$ of the respondents were not aware of the existence of the national reporting system. ${ }^{18}$ Similarly, in China $71 \%$ of the healthcare professionals did not have knowledge of the reporting procedure. ${ }^{6}$ In the European Union (EU), many healthcare professionals did not know how to report an ADR. ${ }^{31}$ These findings suggest the need for awareness program for the healthcare professionals in ADR reporting. The training program should cover the location of the pharmacovigilance center, reporting procedure and method of filling the ADR reporting form. Since ADR reporting might take away the time of the healthcare professionals, in MTH we designed a simple ADR reporting form having the basic information on the patient, suspected drug, the reaction and the reported information. Upon receiving the reports, the pharmacists from the pharmacovigilance center visit the patient or the reporter or collect information from the patient file.

Although $96.6 \%$ of the respondents felt that ADR reporting is important, only one third $(33.7 \%)$ of them reported at least an ADR. In a similar study from Nigeria ${ }^{20}$ only $32 \%$ of the physicians had ever reported an ADR. In China, $28.5 \%$ of doctors and $22.8 \%$ of nurses actually submitted a report. ${ }^{6}$ In Netherlands, only $51 \%$ of the general practitioners and $35 \%$ of the specialists had ever reported an ADR to the national reporting centre. ${ }^{32}$ In Hong Kong, although 93 percent of the pharmacists agreed that it is necessary to report ADRs, only a smaller proportion (14.7\%) had actually reported an
ADR in the previous 12 months. ${ }^{17}$ Since almost every healthcare professional in this study agreed that ADR monitoring is important, there is a huge scope that intervention programs can improve ADR reporting rate in this setting.

The ultimate objective of an ADR monitoring program is to prevent the occurrence of an ADR. In the present study, $39.3 \%$ of the professionals under study had prevented an ADR from occurring. The most common type of drug-induced disorders is dose-dependent and predictable and occurs as a result of drug-drug, drug-disease or drug-food interactions and, therefore, is preventable. ${ }^{33}$ One of the strategies to prevent an ADR is by providing drug information. In MTH the pharmacists run a Drug Information Center (DIC) that provides drug related information to the healthcare professionals of the hospital. ${ }^{34} \mathrm{~A}$ preliminary evaluation of the drug information services provided by the center revealed that nearly one third $(37.7 \%)$ of the drug information queries received were related to drug safety. ${ }^{35}$

Very often, the uncertainty concerning the causal relationship between the ADR and the drug was one of the reasons for under-reporting of ADRs.24 Thus, it becomes necessary to make the healthcare professionals aware of the causality assessment on an ADR. One of the common scales used for causality assessment is the Naranjo algorithm.36 The researcher found only $30.3 \%$ of the healthcare professionals to be aware of the Naranjo algorithm. In order to take appropriate initiatives towards management of the ADR, it is necessary to study the severity of the ADRs. The Hartwig scale ${ }^{37}$ is widely used for this purpose. This scale categorizes the reported ADRs into different levels as mild, moderate or severe based on the treatment and whether or not hospitalization was required for the management of the ADRs. In this study, only $28.1 \%$ of the healthcare professionals were aware of the severity assessment scales. Thus, it becomes mandatory for the educational program to focus on both the causality and severity assessment of the ADRs. Considering its importance, at the Pharmacology Department at Manipal College of Medical Sciences (MCOMS) introduced the causality assessment and severity assessment methods to the undergraduate medical students. ${ }^{38}$

The overall study findings suggest the need for periodic awareness programs for the healthcare professionals in $\mathrm{MTH}$, regarding the ADR monitoring program in the hospital and the ADR reporting procedure. This might improve the KAP of the professionals and the reporting rates. The Drug and Therapeutics Committee (DTC) of the hospital should play a major role in promoting the existing ADR monitoring program in the hospital. Further studies covering the hospitals attached to different regional pharmacovigilance centers in the country might help finding the exact scenario of the health professionals' KAP in this aspect.

Of the total 185 healthcare professionals working in the hospital, only 89 of them were studied. Thus, the findings might or not represent the overall perspectives of the healthcare professionals. 
Moreover, this study was conducted in only one hospital and hence difficult to extrapolate the study findings to the entire country. This study did not compare the KAP scores of the healthcare professionals with their individual ADR reporting rates. Thus, unable to find any relationship between the KAP scores and reporting rates. There were high turnover rates of the healthcare professionals in the hospital. Hence, authors could not plan for an educational intervention for them and study the impact of intervention on the KAP scores.

\section{CONCLUSIONS}

The healthcare professionals at the MTH had a relatively better attitude and practice but limited knowledge towards ADRs and pharmacovigilance. The majority of the healthcare professionals felt ADR monitoring to be important, but only a few had ever reported an ADR to the pharmacovigilance center. The reasons for under-reporting were either they did not come across an ADR or a few were unaware of the existence of a pharmacovigilance center at the hospital. The findings of the study suggest a huge scope for improving the ongoing pharmacovigilance activities in the hospital. There is a need for continuous educational initiatives for the doctors, nurses and the pharmacists.

\section{ACKNOWLEDGMENTS}

Authors acknowledge all the health professionals who participated in this study by filling up the questionnaires.

\section{CONFLICT OF INTEREST}

None declared.

\section{References}

1. Beard K Adverse reactions as a cause of hospital admission in the aged. Drugs Aging. 1992;2(4):356-367.

2. Murphy BM, Frigo LC. Development, implementation, and results of a successful multidisciplinary adverse drug reaction reporting program in a university teaching hospital. Hosp Pharm. 1993;28(12):1199-204,1240.

3. Lazarou J, Pomeranz BH, Corey PN. Incidence of adverse drug reactions in hospitalized patients: a meta-analysis of prospective studies. JAMA. 1998;279(15):1200-1205.

4. Classen DC, Pestotnik SL, Evans RS, Lloyd JF, Burke JP. Adverse drug events in hospitalized patients. Excess length of stay, extra costs, and attributable mortality. JAMA. 1997;277(4):301-306

5. Anonymous. Safety monitoring of medicinal products. The importance of pharmacovigilance. World Health Organization, Geneva, 2002.

6. Li,Q, Zhang SM, Chen HT, Fang SP, Yu X, Liu D, Shi LY, Zeng FD. Awareness and attitudes of healthcare professionals in Wuhan, China to the reporting of adverse drug reactions. Chin Med J (Engl). 2004;117:856-861.

7. Meyboom R, Olsson S, Thorogood M. Teaching pharmacovigilance, In: Pharmacovigilance R.D. Mann, E.B. Andrews, (ed)., John Wiley and Sons, 2002, p.505-508.

8. Anonymous. Safety of Medicines. A guide to detecting and reporting adverse drug reactions, WHO, Geneva, 2002.

9. Hartigan-Go K. Pharmacovigilance and the pursuit of rational drug use: The Philippines experience. Uppsala Reports. $2001 ;(14 \mathrm{~S}): 1-4$.

10. Lee A, Thomas SHL. Adverse drug reactions In: Walker R and Edward C. Clinical pharmacy and Therapeutics. 3rd edition Churchill Livingstone, 2003, p.33-46.

11. Hughes ML, Whittlesea CM, Luscombe DK. Review of national spontaneous reporting schemes. Strengths and weaknesses. Adverse Drug React Toxicol Rev. 2002;21(4):231-241.

12. Anonymous. Validating vigibase online. Uppsala Reports. 2006;(32):10-11.

13. Faich GA. Adverse-drug-reaction monitoring. N Engl J Med. 1986;314(24):1589-1592.

14. Eisenhauer LA. Adverse drug reactions: a concern for clinicians and patients. Clin Excell Nurse Pract. 2002;6:3-7.

15. ASHP guidelines on adverse drug reaction monitoring and reporting. Am J Health Syst Pharm. 1995;52(4):417-419

16. Hazell L, Shakir SA. Under-reporting of adverse drug reactions: a systematic review. Drug Saf. 2006;29(5):385-396.

17. Lee KK, Chan TY, Raymond K, Critchley JA. Pharmacists' attitudes toward adverse drug reaction reporting in Hong Kong. Ann Pharmacother. 1994;28(12):1400-1403.

18. Aziz Z, Siang TC, Badarudin NS. Reporting of adverse drug reactions: predictors of under-reporting in Malaysia. Pharmacoepidemiol Drug Saf. 2007;16(2):223-228.

19. Herdeiro MT, Figueiras A, Polónia J, Gestal-Otero JJ. Physicians' attitudes and adverse drug reaction reporting: a casecontrol study in Portugal. Drug Saf. 2005;28(9):825-833.

20. Okezie E O, Olufunmilayo F. Adverse drug reactions reporting by physicians in Ibadan, Nigeria. Pharmacoepidemiol Drug Saf. 2008;17(5):517-522

21. Lopez-Gonzalez E, Herdeiro MT, Figueiras A. Determinants of under-reporting of adverse drug reactions: a systematic review. Drug Saf. 2009;32(1):19-31.

22. Subish P, Mohamed Izham MI, Mishra P. Evaluation of the knowledge, attitude and practices on adverse drug reactions and pharmacovigilance among healthcare professionals in a Nepalese hospital-a preliminary study. Internet Journal of Pharmacology 2008;6:1

23. Olsson S. The need for pharmacovigilance In: Gupta SK. Pharmacology and therapeutics in the new millennium. Narosa publishing house, New Delhi, 2001, p.502-508. 
24. Irujo M, Beitia G, Bes-Rastrollo M, Figueiras A, Hernández-Díaz S, Lasheras B. Factors that influence under-reporting of suspected adverse drug reactions among community pharmacists in a Spanish region. Drug Saf. 2007; 30(11):107382.

25. Belton K J, Lewis SC, Payne S, Rawlins MD, Wood SM.Attitudinal survey of adverse drug reaction reporting by medical practitioners in the United Kingdom. Br J Clin Pharmacol. 1995;39(3):223-326.

26. Rehan HS, Vasudev K, Tripathi CD. Adverse drug reaction monitoring: knowledge, attitude and practices of medical students and prescribers. Natl Med J India. 2002;15(1):24-26.

27. Graille V, Lapeyre-Mestre M, Montastruc JL. Drug vigilance: opinion survey among residents of a university hospital. Therapie. 1994;49(5):451-454.

28. Cosentino M, Leoni O, Banfi, F, Leechini S, Frigo G. Attitudes to adverse drug reaction reporting by medical practitioners in a Northern Italian district. Pharmacol Res. 1997;35(2):85-8.

29. Bharathan B, Raju, N. A survey about the knowledge, attitude and practice of adverse drug reaction reporting among doctors in Bangalore city. Sixth annual conference of the Society of Pharmacovigilance (India), Kurupanidhi College of Pharmacy, Bangalore, India, 2006.

30. Subish P, Izham M, Mishra P. Pharmacovigilance in Nepal. A guide for healthcare professionals. Regional Pharmacovigilance Centre, Pokhara, Nepal, 2007.

31. Belton K J. Attitude survey of adverse drug-reaction reporting by health care professionals across the European Union. The European Pharmacovigilance Research Group. Eur J Clin Pharmacol. 1997;52(6):423-427.

32. Eland IA, Belton KJ, van Grootheest AC, Meiners AP, Rawlins MD, Stricker BH. Attitudinal survey of voluntary reporting of adverse drug reactions. Br J Clin Pharmacol. 1999;48(4):623-627.

33. Holland EG, Degruy FV. Drug-Induced Disorders. Am Fam Physician. 1997;56(7):1781-1792.

34. Shankar PR, Mishra P, Subish,P, Upadhyay DK. The drug information center at the Manipal teaching hospital- going beyond drug information. Drug Inform J. 2007;41:61-68.

35. Subish P, Mishra P, Shankar PR, Bista D, Purwar B. Contribution of the regional drug information center towards drug safety. JNMA J Nepal Med Assoc. 2006;45(161):216-218.

36. Naranjo CA, Busto U, Sellers EM, Sandor P, Ruiz I, Roberts EA, Janecek E, Domecq C, Greenblatt DJ. A method for estimating the probability of adverse drug reactions. Clin Pharmacol Ther. 1981;30(2):239-245.

37. Hartwig SC, Siegel J, Schneider PJ. Preventability and severity assessment in reporting adverse drug reactions. Am J Hosp Pharm. 1992;49(9):2229-2232.

38. Shankar PR, Subish P, Mishra P, Dubey, AK. Teaching pharmacovigilance to medical students and doctors. Ind J Pharmacol. 2006;38:316-319. 